\title{
Seamless Language Learning in an ESL Context
}

\author{
Siti Noor Azilah Abdullah, Harwati Hashim* \\ Faculty of Education, Universiti Kebangsaan Malaysia, Bangi, Selangor \\ Email: ^harwati@ukm.edu.my
}

How to cite this paper: Abdullah, S. N. A., \& Hashim, H. (2021). Seamless Language Learning in an ESL Context. Creative Education, 12, 1349-1363.

https://doi.org/10.4236/ce.2021.126103

Received: April 7, 2021

Accepted: June 22, 2021

Published: June 25, 2021

Copyright $\odot 2021$ by author(s) and Scientific Research Publishing Inc. This work is licensed under the Creative Commons Attribution International License (CC BY 4.0).

http://creativecommons.org/licenses/by/4.0/ (c) (i) Open Access

\begin{abstract}
Amidst the vigorous development of technology in the Malaysian education scene, the emergence of seamless learning is steadily fitting into the Fourth Industrial Revolution (4IR) teaching and learning settings, particularly in English as a Second Language (ESL) context. At the moment, seamless learning is paving its way for a more effective ESL practice. Seamless learning has the potential to revolutionize teaching and learning by enriching the opportunity of continuous learning. Seamless learning offers the ability for learners to learn whenever they are triggered to especially with the aid of technological tools such as mobile devices. The implementation of technology has continuously shown its advantages to both students and educators. Thus, there is a strong assumption for the concept of seamless learning to be able to produce similar outcomes. This conceptual paper will discuss a few issues revolving the theme of seamless learning for ESL learning which include seamless learning theories followed by the effectiveness of implementing technology for an ESL seamless learning experience. The paper continues and ends with the discussion of seamless learning for ESL learning beyond the classroom. The discussion undertakes a review of past literature in the context of ESL from recent years. This paper will help in providing a clear understanding of seamless learning as well as highlighting the potentials of creating ESL learning beyond the classroom.
\end{abstract}

\section{Keywords}

Seamless Learning, ESL, Technology in Education, 4IR Education, Continuous Learning

\section{Introduction}

The endless advancement of technology in this 4IR era has encouraged educators to venture on various opportunities and possibilities in order to create effective teaching and learning practices (Ilomäki \& Lakkala, 2018). It has inevitably 
ensured the consistent growth in the education field through countless innovation which also includes an ESL teaching and learning setting (Mofareh, 2019). The phenomenal development rate of technology in education has tremendously supported the notion of continuous and seamless learning in which learners could learn anywhere and anytime (Foomani \& Hedayati, 2016). Due to this fortunate event, seamless learning which celebrates the idea of allowing learners to learn when they are triggered to learn without having any boundary has emerged.

Seamless learning can be defined as an experience in which learners are able to learn in a continuous manner while involuntarily bridging various learning efforts with a combination of various times, locations as well as technologies (Wong et al., 2015). The existence of technology such as mobile devices allows learning to take place at the end of the learners' fingertips (Dias \& Victor, 2017). Mobile device is no longer a foreign tool or merely an accessory. It is now a part of our way of life (Hashim, 2018). It would be such a waste for educators and learners to not take advantage of the benefits offered by technology such as mobile devices in order to improve ESL teaching and learning practices.

In the upcoming years, it is assumed that technologies such as mobile devices to consistently become more valuable to users in terms of their personal and social lives, and it will be hard for users to go through every day without the technology (Krull \& Duart, 2017). When we look into our day-to-day routine with our mobile devices, various activities can be looked at as learning opportunities (García-Martinez et al., 2019). Activities such as video watching, Internet browsing, and interacting with other mobile users are considered as a part of learning resources and contexts (Damyanov \& Tsankov, 2018).

Each and every activity mentioned previously offers various opportunities for ESL learners to improve their English language learning. For instance, watching videos available on online platforms has shown that it could provide opportunities for second language learners to learn authentic English (Morat et al., 2017). Other than that, gaining resources from online web browser is invaluable in assisting self-directed learning among learners by providing information that suits their professional interests and needs for ESL learning (Erenchinova \& Proudchenko, 2017). Finally, online interaction between one mobile user to another allows learners to practice using the English language in real world situations (Nishanthi, 2018). As mentioned by Halim et al. (2018), learners' exposure to different opportunities of interaction with others will enhance their language learning.

Seamless learning can also be described as a learning "space" that switches between formal and informal learning as well as between individual and social learning in a smooth or seamless manner (Looi et al., 2010). Looi et al. (2010) also stated that nowadays, it has become a trend among educators to spark learning interests among English language learners by practicing the use of technology in classrooms. The use of Massive Open Online Courses (MOOC), for example, has connected the formal learning experience to the diffusion of 
mobile technologies (Cha \& So, 2020). Seamless learning enables learners to relate information that they have learned in a formal classroom into their daily lives with the use of appropriate technological tools (Looi et al., 2016).

This paper will further discuss issues related to seamless learning in an ESL context and mainly focuses on English language learning beyond the classroom. The discussion will start seamless learning theories followed by the effectiveness of implementing technology for an ESL seamless learning. The discussion will be continued and closed with seamless learning for ESL learning beyond the classroom.

\section{Literature Review}

\subsection{Seamless Learning Theories}

\subsubsection{Behaviourism}

Behaviourism is a theory where it is believed that learning can be evaluated through changes in learners' behaviour (Skinner, 1968). Budiman (2017) on the other hand stated that behaviourism highlights the process of learning as gaining input in the form of stimulus and producing output in the form of response. In a more specific term, the theory of behaviourism focuses on how learners respond to a particular stimulus that can be evaluated, quantified and controlled when repeated (Picciano, 2017).

Jabir (2018) mentioned in an article that ESL learning is an involuntary process in which learners acquire the language automatically and unconsciously. $\mathrm{He}$ also mentioned that behaviourist learning strategy promotes the "habit formation" for ESL learning. It can be seen that seamless learning supports the theory of behaviourism as it important for learners to opt to a more seamless learning experience when learning has become unconscious and habitual.

In an ESL learning context, it is believed that learning occurs when learning itself causes changes in learners' behaviour, for instance when they are able to produce oral or written product from the stimulus that is controlled by the teacher (Budiman, 2017). It is suggested that the implementation of technology through seamless learning is able to enhance behaviourist learning process (Hashim, 2016). The use of technology such as mobile device for ESL learning allows students to receive and give immediate feedback without being bound by time and location (MacCallum \& Parsons, 2016). ESL learning through online applications on mobile devices for instance, will play the role of the stimulus while learners' responses through this medium will be the response.

\subsubsection{Constructivism}

Constructivism theory emphasizes on how learners are able to build their understanding through their own experiences (Jobrack, 2013). It is believed that humans can only understand things that they construct on their own (Har, 2005; Mohammed \& Kinyo, 2020). Constructivist learning and teaching perspective represents a shift from viewing learners as responding to external stimuli to seeing learners as "active in constructing their own knowledge"; they assert that 
"social interactions are important in knowledge construction" (Bruning et al., 2004). Constructivism in other words promotes the idea that learners construct their own knowledge and understanding through experience.

As stated by George E. Hein (1991), constructivism theory requires teacher to provide learners with activities, hands-on learning, opportunities to experiment and manipulate the objects of the world, but the main objective is definitely to expose learners to independent learning. Seamless learning promotes the theory of constructivism by encouraging student-centered learning where students hold the responsibility of doing; exploring and experiencing learning while teacher only guides and facilitates the students (Kapur, 2019a). Through the implementation of mobile device in seamless learning, students are able to conduct their own learning whenever they are triggered by their daily experiences and build on their existing knowledge.

Based on the theory of constructivism, it provides learners with the opportunity of interaction with sensory data and constructing their own world (Hein, 1991). Through the use of technology, learners are able to experience more than merely passive learning in the classroom and with seamless learning, they can expand their learning outside of the classroom at the convenience of their own time and space. Constructivism theory also promotes the idea of students being able to gather information as their prior knowledge and later on construct their ideas in order to create an effective learning (Aljohani, 2017). Seamless learning definitely supports this notion where it encourages learning to seamlessly flow from one medium to another. Thus, once learners received the information in the classroom, they can seamlessly venture to a different medium such as mobile device to further explore and expand on the information.

\subsubsection{Connectivism}

As today's teaching and learning continue to revolve around the implementation of technology, the theory of connectivity was developed and was first introduced by George Siemens in 2005. It is the currently the most recent learning theory which is built to suit the 21 st Century teaching and learning. As mentioned by Corbett \& Spinello (2020), the connectivism theory was developed because Siemens finds that the existing learning theories are insufficient for the digital age as most of the theories were built without the consideration of technology. Hence, there is a solemn need for a learning theory that is advanced and up to date.

Basically, connectivism is a knowledge and learning theory which promotes learning through network and emphasizes on technology usage in order to promote online interactions (Downes, 2019). According to the founder of the theory of connectivism, "learning is a process of connecting specialized nodes or information sources" (Siemens, 2005). Connectivism believes in the notion that learning are not bound by any specific location but instead consists of networks of connections constructed from experience and interactions among learner, technologies and their surroundings (Goldie, 2016). 
The theory of connectivism strongly links to the principle of seamless learning which promotes continuous and seamless learning leaping across the boundary of time and space (Xin et al., 2018). Siemens (2005) mentioned that knowledge in today's world keeps on changing and developing. Hence, learning should be continuous and is able to be accessed anytime and anywhere a learner is triggered. Through seamless learning, learners are enabled to continuously learn and expand on their knowledge at their own convenience without interrupting their learning flow. This is possible as seamless learning allows learning to occur in- and out-of-class as well as shifting from one medium to the other seamlessly.

\subsection{The Effectiveness of Implementing Technology for an ESL Seamless Learning Experience}

In the ever-changing era of vigorous development of technology, the implementation of technology in education, specifically in the ESL learning context, has continuously shown to bring more benefit than harm to learners' learning experience (Halim \& Hashim, 2019). According to Parvin and Salam (2015), the education field has progressively opened up to innovative ways of teaching, learning and acquiring knowledge and it is now considered unusual for ESL teaching and learning to not include technology in its execution.

Various studies have proven that the implementation of technology in ESL learning could increase learners' motivation. A study by Barreto (2018) showed the use of technology such as online learning platforms, specifically MOODLE and MIND4 which were used in this study has elevated learners' motivation to produce English writing products. They also reacted positively towards the use of technology in English language learning as it enables them to collaboratively work with their peers. Most importantly, the result of this study showed that the implementation of technology has significantly increase learners' language learning as they felt more focused, and learning seemed more planned and easier to be comprehended.

On a different study by Abdullah et al. (2018), a quantitative study was carried out to 60 students which were divided into two groups: controlled and uncontrolled group. The controlled group was exposed to the use of social media platform, Pinterest in order to aid learners' pre-writing stage. From the results, respondents from the controlled group showed an increased achievement in the post-test with $73.34 \%$ scored above "Good" score band. Other than that, the respondents also stated that a majority of respondents reacted positively towards using Pinterest where $86.7 \%$ agreed that Pinterest ease the process of writing essay and $80 \%$ agreed that they are able to stay focused when using Pinterest.

Another recent study by Layali and Al-Schlowiy (2020), a quantitative study was carried out to 21 female students of Imam Abdulrahman University. Due to the Covid-19 pandemic outbreak, all physical classes were switched to online platforms and this study has chosen Google Docs as a Cloud-based Collaborative Writing (CBCW) platform and Telegram for language learning. From the results, a majority of the respondents stated that they were in favour of Google 
Docs as it improved their writing quality. Also, learners found that they were able to increase their vocabulary when using Telegram for language learning.

The ability of technology in providing ease and accessibility for students to shift from one learning medium to another has created an opportunity for seamless learning to emerge. The possibility of learning anytime and anywhere is will definitely increase the chance of improving ESL learning. Language learning should no longer be restricted solely in the classroom where learning is teacher-centred but learning should be able to occur whenever learners are triggered and intrigued to do so.

\subsection{Seamless Learning for ESL Learning Beyond the Classroom}

\subsubsection{Bridging Formal and Informal Learning}

Formal learning occurs in a classroom setting where learners learn about a particular subject or topic as planned by teachers which is usually driven by the need to cover compulsory syllabus (Looi et al., 2016). They also stated that informal learning occurs outside of the classroom such as at home where learners experience learning in a more natural setting or in different contexts. Formal learning or in-class learning is often considered as the core setting for ESL learning because it is mainly controlled and facilitated by the teacher (Kapur, 2019b). However, informal learning executed in a self-directed learning situation is just as important in ensuring an effective ESL learning experience (Ismail \& Shafie, 2019). As mentioned by Tim Boileau (2017), learning that occurs based on prior experiences and knowledge will enable learners to expand the knowledge that they are learning.

Manuti et al. (2015) stated that at any moment when learning occurs, the elements of formal and informal learning are both present. Thus, this leads to a seamless learning situation where formal and informal learning is bridged and intertwined between one another in a seamless manner. It is important to recognize that seamless learning is able to take place in both formal and informal classroom settings. However, with the support of the endless development of technology, learning can now be carried out whenever learners are triggered to learn with the aid of mobile devices at any time and location (Lewin \& Cherania, 2018). The implementation of technology in teaching and learning enables formal and informal learning to be bridged which leads to the emergence of a seamless learning experience.

Seamless learning enables learners to connect their in-class experience to out-of-class learning without any boundary (Mouri et al., 2018; Hiew et al., 2018). Amhag (2017) mentioned that seamless learning ensures that learning time could be prolonged from formal to informal learning. This means that although class period may have ended due to time constraints, learners can still easily continue their learning by accessing to additional information through their mobile device from out of the classroom. Access to Internet and mobile devices allows learners to connect, share and discuss topics related to their learning anytime and anywhere (Traxler, 2016). The luxury of being able to have unli- 
mited access to information nowadays creates an opportunity for learners to learn whenever they feel intrigued and interested to learn.

Czerkawski (2016) mentioned that learners connect and associates their learning interests with their personal life as if it was involuntary and the two interchange in such a natural setting due to the fact that technology such as mobile device, for instance, has become a huge part of our daily lives. The bridging of formal and informal learning in some way "blurred" the differences between in-class and out-of-class learning (Dron \& Anderson, 2014). Thus, this leads to a seamless learning experience which ensures that learners no longer have the boundary in terms of time and location in order to learn. The bridging of formal and informal learning also enables learners to experience learning within their own capabilities as well as at their own convenience. The bridging of in- and out-of-class learning is enabled by various interactive learning contents that are available on mobile devices which can be accessed by learners (Hwang \& Lai, 2017). For instance, during a formal classroom period, learners will experience a structured English lesson as prepared by the teacher. However, the learning should not just end there once the period is over, but it should and needs to be supplemented and expanded in an informal learning setting (Marsenille, 2017).

The continuity from formal to informal learning should be natural and feel like a part of their daily experience rather than forced and planned because this matter will make learning be more meaningful to learners (Looi et al., 2016). Rogoff et al. (2016) who are of the same opinion stated that the continuation of learning from a formal to an informal setting helps learners to further build and expand on the knowledge that they learned in class as they are able to learn in a natural and nondidactic manner based on their own choice and initiative. This matter is also highlighted by Donovan et al. (2018) in which it was stated that when learners are able to create a learning experience that feels natural to them, they will be able to attain better understanding of what they are learning rather than being constrained by rigid timing and learning outcomes.

\subsubsection{Creating Autonomous Learners}

Yunus et al. (2019) mentioned in an article that learners in today's education realm should become autonomous learners and be responsible of their own learning especially with the accessibility of technology to aid the learning process. Reinders and White (2016) stated that the reconceptualization of autonomous learning nowadays is led by the growing interest towards technology-enhanced learning as well as the unceasing development of technology. As previously discussed, in ESL learning, it is important for learners to conduct self-directed learning in order to effectively master the language (Parisi, 2020). However, self-directed learning requires learners to be autonomous learners who are fully in control of their own learning (Alzubi et al., 2017).

It is without a doubt that seamless learning is able to create and produce ESL learners who competent to learn English autonomously. As suggested by Milrad et al. (2013), seamless learning is a learning process that provides limitless access 
to learners which could also enable a self-learning experience in various learning situations with the support of technology. This means that seamless learning encourages self-directed learning by enabling learners to learn at their own convenience of time and space. Seamless learning promotes a learning experience where learners are able to conduct individual learning that allows learning to be carried out within the learners' control (Ozdamli, 2013). For instance, seamless learning may occur when learners browse through the web on their mobile device at home as they recall something from their previous English lesson. Seamless learning enables them to continuously and independently strengthen their learning experience by connecting the knowledge they have learned in-class to their natural setting (Wong et al., 2017).

The aid of technology in learning produces autonomous learners who are in control of their own learning and are not constrained by any planned learning structure (Min \& Nasir, 2020). Autonomous learning or self-directed learning in an informal learning setting has frequently been proven to have a positive effect for learners (Kaput, 2018). It is able to improve learners' achievement in learning as well as interaction between peers and teacher (Hwang \& Lai, 2017). In an ESL context, it is important for learners to conduct self-directed learning especially with the aid of technology like mobile devices as it will provide more space and opportunity for learners to practice the English language (Hawkins, 2018). Thus, it can be seen that seamless learning enhances the opportunity for English language learners to learn autonomously.

The implementation of technology in English language learning which leads to seamless learning is believed to be able to encourage student-centered learning (Lan, 2017). Valentine (2016) on the other hand found that by having the opportunity of being in control of their own learning, learners have more desire to supplement and enhance their learning involuntarily. This shows that seamless learning is able to increase learners' interest in conducting self-directed learning when they possess the ability of learning at their own convenience of time and space (Foomani \& Hedayati, 2016).

\subsubsection{Shifting to and from Various Learning Contexts with Seamless Learning}

ESL learning in this era of endless advancement of technology goes beyond the four walls of the classroom (Tavakoli et al., 2016). By now, we have already grasped the idea of seamless learning with its notion of promoting learning that exceeds the boundary of time and location and enables learning to happen anytime and anywhere with the assistance of technology. As stated by Safiah et al. (2020), seamless learning with the support of technology such as mobile devices allow learners to learn across different learning context where they could learn without any limit in terms of time and location. The ability of having unlimited access to learning leads to the ability for learners to experience continuous learning which means that learners are able to learn continuously even though they are not in a formal classroom setting. 
Referring to Wong et al. (2015), seamless learning occurs when learners experience a continuity of learning by bridging various learning efforts and shifting between various learning context with a combination of different spaces, times, technologies and social surrounding. There are various ways for learning to occur by seamlessly shifting from one learning context to the other (Griesbaum, 2017). According to Sharples (2015), the shift between one learning context to another may be intentional or even accidental. The shift might be intentional, for instance when learning continues as planned from attaining information from the classroom and proceeding with application through given homework while the shift could also be accidental when for instance, the teacher recalls an information from a TV program and use it as steppingstone to further explore the information through discussion in class with the learners (Sharples, 2015). $\mathrm{He}$ also stated that the whole learning experience is still considered seamless though learners may realize the connection between the different contexts used as long as the experience is separated from specific time and location.

Other than that, the shift may also seamlessly occur from one device to another. It should be understood that learners in today's education scene have the ability to use various mobile and digital devices to aid their learning (Krull \& Duart, 2019). Krull and Duart (2019) also found in their study that learners practice using their mobile devices in a sequential manner, for example, learner may have started their learning using their first device, but later decided to continue or complete the learning on another mobile device. They also identified the patterns among learners that use their device in a sequential manner. The patterns are as follows:

1) Students need to move between different locations.

2) Students decide to move to a different learning activity.

3) Students want to continue the same learning activity at a later stage.

4) Students need to move between devices because of device features.

In this 4IR era, it is only beneficial for learners to have unlimited access to learning (Raja \& Nagasubramani, 2018). Seamless learning allows learners to experience a continuity in learning without being bound by the constraints of time and location. As mentioned by Safiah et al. (2020), seamless learning allows learning to run seamlessly by encouraging learning continuity across different contexts. Learners are able to shift from one learning context to the other by merely a touch on their mobile device. Hence, seamless learning is perfect for today's learners as it helps in expanding learners' learning space from one learning context to another (Barden \& Bygroves, 2017; Song, 2018).

\section{Conclusion}

Finally, it may be concluded that seamless learning holds great potential to create a more effective and beneficial language learning for learners, particularly in ESL. The bridging of formal and informal learning will be able to ensure that ESL learners can learn seamlessly at their own convenience of time and space, 
and most importantly in the most natural learning setting. Learning in a real-life situation and environment will be able to provide learners with the most ideal and conducive learning experience. Learning in the most conducive environment should be able to provide a better chance for learners achieve better language attainment.

Other than that, seamless learning also creates autonomous learners and promotes student-centered learning which is very important in this age of 4IR. There is no longer a need for learners to be spoon-fed by teachers. Learners must be responsible of their own learning especially when everything is at the end of their fingertips. Autonomous learners have a better chance of having a successful and effective language learning experience rather than learners who rely entirely on formal classroom learning.

Last but not least, the shifting from one learning context to the other leads to learners experiencing language learning in a seamless manner. The accessibility to technology is able to help learners shift between different learning contexts seamlessly without being bound by different times and locations. The experience of learning without being constrained by time and space gives learners the flexibility of being in charge of their own learning. Learners will feel more motivated and intrigued to learn whenever they are triggered by the curiosity for knowledge when they are in control of their own learning.

Therefore, teachers and learners especially in ESL should take the opportunity provided through seamless learning to enhance the English learning experience. The technology that we have implemented in our everyday lives, such as our mobile devices should also be applied into learning and put into good use. These mobile devices when used in the right way and intention will not only ease the learning process but also create the best learning experience that is fruitful and would benefit learners for a lifetime.

\section{Acknowledgements}

The authors would like to acknowledge Ministry of Higher Education Malaysia (MOHE) under the Fundamental Research Grant Scheme (FRGS) with project code no. FRGS/1/2019/SS09/UKM/02/2 for the financial support of this research and Universiti Kebangsaan Malaysia under research grant No. GG-2020-027.

\section{Conflicts of Interest}

The authors declare no conflicts of interest regarding the publication of this paper.

\section{References}

Abdullah, S., Hashim, H., \& Sofwan Mahmud, M. (2018). Using Mobile Application as an Alternative to Pre-Writing Strategy. International Journal of Engineering and Technology, 7, 143-147.

Aljohani, M. (2017). Principles of Constructivism in Foreign Language Teaching. Journal of Literature and Art Studies, 7, 97-107. 
https://doi.org/10.17265/2159-5836/2017.01.013

Alzubi, A. A. F., Singh, M. K. M., \& Pandian, A. (2017). The Use of Learner Autonomy in English as a Foreign Language Context among Saudi Undergraduates Enrolled in Preparatory Year Deanship at Najran University. Advances in Language and Literary Studies, 8, 152-160. https://doi.org/10.7575/aiac.alls.v.8n.2p.152

Amhag, L. (2017). Mobile-Assisted Seamless Learning Activities in Higher Distance Education. International Journal of Higher Education, 6, 70-81. https://doi.org/10.5430/ijhe.v6n3p70

Barden, O., \& Bygroves, M. (2017). “I Wouldn't Be Able to Graduate If It Wasn't for My Mobile Phone." The Affordances of Mobile Devices in the Construction of Complex Academic Texts. Innovations in Education and Teaching International, 55, 555-565. https://doi.org/10.1080/14703297.2017.1322996

Barreto, A. M. R. (2018). Motivating English Language Use by Using the Benefits of Technology. Gist Education and Learning Research Journal, No.16, 117-140. https://doi.org/10.26817/16925777.428

Boileau, T. (2017). Informal Learning: Lifelong Learning in the 21st Century. Pensacola, FL: University of West Florida.

Bruning, R., Schraw, B., Norby, M., \& Ronning, R. R. (2004). Cognitive Psychology and Instruction. Upper Saddle River, New Jersey: Pearson.

Budiman, A. (2017). Behaviorism in Foreign Language Teaching Methodology. English Franca, 1, 101-114. https://doi.org/10.29240/ef.v1i2.171

Cha, H., \& So, H. J. (2020). Integration of Formal, Non-Formal and Informal Learning through MOOCs. In D. Burgos (Eds.), Radical Solutions and Open Science (pp. 135-158). Singapore: Springer. https://doi.org/10.1007/978-981-15-4276-3 9

Corbett, F., \& Spinello, E. (2020). Connectivism and Leadership: Harnessing a Learning Theory for the Digital Age to Redefine Leader in the Twenty-First Century. Heliyon, 6, Article ID: E03250. https://doi.org/10.1016/j.heliyon.2020.e03250

Czerkawski, B. C. (2016). Blending Formal and Informal Learning Networks for Online Learning. International Review of Research in Open and Distributed Learning, 17, 138-156. https://doi.org/10.19173/irrodl.v17i3.2344

Damyanov, I., \& Tsankov, N. (2018). Mobile Apps in Daily Learning Activities. International Journal of Interactive Mobile Technologies, 12, 133-140. https://doi.org/10.3991/ijim.v12i6.9659

Dias, L., \& Victor, A. (2017). Teaching and Learning with Mobile Devices in the 21st Century Digital World: Benefits and Challenges. European Journal of Multidisciplinary Studies, 2, 339-344. https://doi.org/10.26417/ejms.v5i1.p339-344

Donovan, G. H., Michael, Y. L., Gatziolis, D., \& Hoyer, R. W. (2018). The Relationship between the Natural Environment and Individual-Level Academic Performance in Portland, Oregon. Environment and Behavior, 52, 164-186. https://doi.org/10.1177\%2F0013916518796885

Downes, S. (2019). Recent Work in Connectivism. European Journal of Open, Distance and E-Learning, 22, 112-131. https://doi.org/10.2478/eurodl-2019-0014

Dron, J., \& Anderson, T. (2014). Teaching Crowds: Learning and Social Media. Edmonton, AB: Athabasca University Press. https://doi.org/10.15215/aupress/9781927356807.01

Erenchinova, E., \& Proudchenko, E. (2017). Advantages of WEB Resources Use in Learning Process. Proceedings of the 7th International Scientific and Practical Conference "Current Issues of Linguistics and Didactics: The Interdisciplinary Approach in 
Humanities" (CILDIAH 2017), Volgograd, 10-12 May 2017, 103-108.

Foomani, M. E., \& Hedayati, M. (2016). A Seamless Learning Design for Mobile Assisted Language Learning: An Iranian Context. Canadian Center of Science and Education. English Language Teaching, 9, 206-213. https://doi.org/10.5539/elt.v9n5p206

García-Martínez, I., Fernández-Batanero, J. M., Sanchiz, D. C., \& de la Rosa, A. L. (2019). Using Mobile Devices for Improving Learning Outcomes and Teachers' Professionalization. Sustainability (Switzerland), 11, 1-12. https://doi.org/10.3390/su11246917

Goldie, J. G. S. (2016). Connectivism: A Knowledge Learning Theory for the Digital Age? Medical Teacher, 38, 1064-1069. https://doi.org/10.3109/0142159X.2016.1173661

Griesbaum, J. (2017). Trends in e-Learning: Impacts of Social Mobile Technologies of Information Behavior, Formal Learning and the Educational Market. International Journal of Information and Education Technology, 7, 123-129. https://doi.org/10.18178/ijiet.2017.7.2.853

Halim, M. S. A. A., \& Hashim, H. (2019). Integrating Web 2.0 Technology in ESL Classroom: A Review on the Benefits and Barrier. Journal of Counselling and Educational Technology, 2, 19-26. https://doi.org/10.32698/0381

Halim, S. Z. S. A., Haiqal, M. I., Yunus, M. M., \& Mohamad, M. (2018). Skype in the Classroom: An Online Collaboration Awareness Campaign to Develop Speaking Skill. International Journal of Innovative Research and Creative Technology, 4, 57-61.

Har, L. B. (2005). Constructivist Learning and Teaching. Hong Kong: The Hong Kong Institute of Education.

Hashim, H. (2016). Factors Affecting Malaysian Polytechnic English as a Second Language (ESL) Learners' Attitude and Intention for Using Mobile Learning. Bangi: Universiti Kebangsaan Malaysia.

Hashim, H. (2018). Application of Technology in the Digital Era Education. International Journal of Research in Counselling and Education, 2, 1-5. https://doi.org/10.24036/002za0002

Hawkins, M. W. (2018). Self-Directed Learning as Related to Learning Strategies, Self-Regulation, and Autonomy in an English Language Program: A Local Application with Global Implications. Studies in Second Language Learning and Teaching, 8, 445-469. https://doi.org/10.14746/ssllt.2018.8.2.12

Hein, G. E. (1991). Constructivist Learning Theory. Paper presented at the CECA (International Committee of Museum Educators) Conference, Jerusalem Israel, 15-22 October 1991, 1-10.

Hiew, F. C., Sheard, J., Parthiban, R., \& Chew, E. (2018). How Seamless are Technology-rich Learning Environments? The Voice of UT Educators. Proceedings of the 23rd Annual ACM Conference on Innovation and Technology in Computer Science Education (ITiCSE 2018), Larnaca, 2-4 July 2018, 218-223. https://doi.org/10.1145/3197091.3197125

Hwang, G. J., \& Lai, C. L. (2017). Facilitating and Bridging Out-of-Class and In-Class Learning: An Interactive E-Book Based Flipped Learning Approach for Match Courses. Educational Technology \& Society, 20, 184-197.

Ilomäki, L., \& Lakkala, M. (2018). Digital Technology and Practices for School Improvement: Innovative Digital School Model. Research and Practice in Technology Enhanced Learning, 13, Article No. 25. https://doi.org/10.1186/s41039-018-0094-8

Ismail, I. S., \& Shafie, N. H. (2019). English Informal Language Learning through Social Networking Sites among Malaysian University Students. Asian Journal of University 
Education, 15, 211-225. https://doi.org/10.24191/ajue.v15i3.7800

Jabir, M. (2018). Behaviorism and Cognitivism in Teaching of English as a Second Language. International Journal of English Language, Literature and Translations Studies, 5, 47-53.

Jobrack, B. (2013). The 5E Instructional Model: Engage Explore Explain Evaluate Extend. From Science, Technology, Engineering and Mathematics.

http://eteamscc.com/wp-content/uploads/2015/07/Overview-of-5E-Instructional-Mode 1.pdf

Kapur, R. (2019). Constructivism in Teaching-Learning Process. Delhi: University of Delhi.

Kapur, R. (2019). Understanding the Meaning and Significance of Formal Education. Delhi: University of Delhi.

Kaput, K. (2018). Evidence for Student-Centered Learning. Saint Paul, MN: Education Evolving.

Krull, G., \& Duart, J. M. (2017). Moving to Seamless Learning: A Framework for Learning Using Multiple Devices. In R. Power, M. Ally, D. Cristol, \& A. Palalas (Eds.), IAmLearning: Mobilizing and Supporting Educator Practice. Mile End: International Association for Mobile Learning. https://iamlearning.pressbooks.com/

Krull, G., \& Duart, J. M. (2019). Supporting Seamless Learning: Exploring Patterns of Multiple Device Use in an Open and Distance Learning Context. Research in Learning Technology, 27, 1-13. https://doi.org/10.25304/rlt.v27.2215

Lan, Y. J. (2017). Technology Enhanced Learner Ownership and Learner Autonomy through Creation. Educational Technology Research and Development, 66, 859-862. https://doi.org/10.1007/s11423-018-9608-8

Layali, K., \& Al-Shlowiy, A. (2020). Students' Perceptions of e-Learning for ESL/EFL in Saudi Universities at Time of Coronavirus: A Literature Review. Indonesian EFL Journal, 6, 97-108. https://doi.org/10.25134/ieflj.v6i2.3378

Lewin, C., \& Charania, A. (2018). Bridging Formal and Informal Learning through Technology in the Twenty-First Century: Issues and Challenges. In J. Voogt, G. Knezek, R. Christensen, \& K. W. Lai (Eds.) Second Handbook of Information Technology in Primary and Secondary Education (pp. 199-125). Cham: Springer. https://doi.org/10.1007/978-3-319-71054-9_13

Looi, C. K., Lim, K. F., Pang, J., Seow, P., Sun, D., Boticki, I., Norris, C., \& Soloway, E. (2016). Bridging Formal and Informal Learning with the Use of Mobile Technology. In C. S. Chai, C. P. Lim, \& C. M. Tan (Eds.), Future Learning in Primary Schools: A Singapore Perspective (pp. 79-96). Singapore: Springer. https://doi.org/10.1007/978-981-287-579-2 6

Looi, C. K., Seow, P., Zhang, B., \& So, H. J. (2010). Leveraging Mobile Technology for Sustainable Seamless Learning: A Research Agenda. British Journal of Educational Technology, 41, 154-169. https://doi.org/10.1111/j.1467-8535.2008.00912.x

MacCallum, K., \& Parsons, D. (2016). A Theory-Ology of Mobile Learning: Operationalizing Learning Theories with Mobile Activities. 15th World Conference on Mobile and Contextual Learning, Sydney, 24-26 October 2016, 173-182.

Manuti, A., Pastore, S., Scardigno, A. F., Giancaspro, M. L., \& Morciano, D. (2015). Formal and Informal Learning in the Workplace: A Research Review. International Journal of Training and Development, 19, 1-17. https://doi.org/10.1111/ijtd.12044

Marsenille, A. V. (2017). Informal Learning Activities for Learners of English and for Learners of Dutch. In Q. Kan, \& S. Bax (Eds.), Beyond the Language Classroom: Re- 
searching MOOCs and Other Innovations (pp. 141-152). Voillans: Research-Publishing. https://doi.org/10.14705/rpnet.2017.mooc2016.677

Milrad, M., Wong, L.-H., Sharples, M., Hwang, G.-J., Looi, C.-K., \& Ogata, H. (2013). Seamless Learning: An International Perspective on Next Generation Technology Enhanced Learning. In Z. L. Berge, \& L. Y. Muilenburg (Eds.), The Handbook of Mobile Learning (pp. 95-108). New York, NY: Routledge.

Min, H., \& Nasir, M. K. M. (2020). Self-Regulated Learning in A Massive Open Online Course: A Review of Literature. European Journal of Interactive Multimedia and Education, 1, Article No. e02007. https://doi.org/10.30935/ejimed/8403

Mofareh, A. A. (2019). The Use of English in English Language Teaching. Frontier in Education Technology, 2, 168-180.

Mohammed, S. H., \& Kinyo, L. (2020). The Role of Constructivism in the Enhancement of Social Studies Education. Journal of Critical Reviews, 7, 249-256. https://doi.org/10.31838/jcr.07.07.41

Morat, B. N., Shaari, A., Abidin, M. J. Z., \& Abdullah, A. (2017). Youtube within ESL Classroom: Exploring an Instructor's and Her Learners' Experiences Concerning the Authenticity of Language and Technology Use. Malaysian Journal of Learning and Instruction, Special Issues 2017, 173-196. https://doi.org/10.32890/mjli.2017.7802

Mouri, K., Uosaki, N., \& Ogata, H. (2018). Learning Analytics for Supporting Seamless Language Learning Using E-Book with Ubiquitous Learning System. Journal of Educational Technology \& Society, 21, 150-163. http://www.jstor.org/stable/26388390

Nishanthi, R. (2018). The Importance of Learning English in Today World. International Journal of Trend in Scientific Research and Development, 3, 871-874. https://doi.org/10.31142/ijtsrd19061

Ozdamli, F. (2013). Effectiveness of Cloud Systems and Social Networks in Improving Self-Directed Learning Abilities and Developing Positive Seamless Learning Perceptions. Journal of Universal Computer Science, 19, 602-618.

Parisi, J. (2020). Self-Directed Learning Practices in ESL: How Beginning Adult Latinx English Language Learners Can Increase Learning Outcomes. San Francisco, CA: The University of Francisco.

Parvin, R. H., \& Salam, S. F. (2015). The Effectiveness of Using Technology in English Language Classrooms in Government Primary Schools in Bangladesh. Forum for International Research in Education, 2, 47-59. https://doi.org/10.18275/fire201502011049

Picciano, A. G. (2017). Theories and Frameworks for Online Education: Seeking an Integrated Model. Online Learning, 21, 166-190. https://doi.org/10.24059/olj.v21i3.1225

Raja, R., \& Nagasubramani, P. C. (2018). Impact of Modern Technology in Education. Journal of Applied and Advanced Research, 3, 33-35.

Reinders, H., \& White, C. (2016). 20 Years of Autonomy and Technology: How Far Have We Come and Where to Next? Language Learning \& Technology, 20, 143-154. http://hdl.handle.net/10652/3552

Rogoff, B., Callanan, M., Gutierrez, K. D., \& Erickson, F. (2016). The Organization of Informal Learning. Review of Research in Education, 40, 356-401. https://doi.org/10.3102\%2F0091732X16680994

Safiah, I., Degeng, I. N. S., Setyosari, P., \& Ulfa, S. (2020). Design and Development of Seamless Learning to Improving Learning Outcome of Islamic Economic Course: A Case Study in Indonesia. Journal of e-Learning and Knowledge Society, 16, 60-67.

Sharples, M. (2015). Seamless Learning Despite Context. In L.-H. Wong, M. Milrad, \& M. Specht (Eds.), Seamless Learning in the Age of Mobile Connectivity (pp. 41-55). Sin- 
gapore: Springer. https://doi.org/10.1007/978-981-287-113-8 2

Siemens, G. (2005). Connectivism: A Learning Theory for the Digital Age. International Journal of Instructional Technology and Distance Learning, 2, 3-10.

Skinner, B. F. (1968). The Technology of Teaching. New York, NY: Appleton-CenturyCrofts.

Song, Y. (2018). Improving Primary Students' Collaborative Problem Solving Competency in Project-Based Science Learning with Productive Failure Instructional Design in a Seamless Learning Environment. Educational Technology Research and Development, 66, 979-1008. https://doi.org/10.1007/s11423-018-9600-3

Tavakoli, N., Shakeri, N., \& Ghanbarzadeh, T. (2016). Language Learning beyond the Classroom. Journal of International Education in Business, 4, 153-162.

Traxler, J. (2016). Inclusion in an Age of Mobility. Research in Learning Technology, 24, Article No. 31372. https://doi.org/10.3402/rlt.v24.31372

Valentine, D. L. (2016). Examining Bridges between Informal and Formal Learning Environments: A Sequential Mixed Method Design. Master's Thesis, Lincoln: University of Nebraska-Lincoln.

Wong, L. H., Chai, C. S., \& Poh, A. G. (2017). Seamless Language Learning: Second Language Learning with Social Media. Comunicar, 50, 9-21.

https://doi.org/10.3916/C50-2017-01

Wong, L. H., Chai, C., Aw, G., \& King, R. (2015). Enculturating Seamless Language Learning through Artifact Creation and Social Interaction Process. Interactive Learning Environments, 23, 130-157. https://doi.org/10.1080/10494820.2015.1016534

Xin, Y., Zuo, X., \& Huang, Q. (2018). Research on the Construction of Seamless Learning Platform Based on Open Education. Asian Association of Open Universities Journal, 13, 88-99. https://doi.org/10.1108/AAOUJ-01-2018-0005

Yunus, M. M., Hashim, H. U., \& Hashim, H. (2019). Massive Open Online Courses: En Route to Communication Skills Acquisition. Arab World English Journal (AWEJ) Special Issue on CALL, No. 5, 98-109. https://doi.org/10.24093/awej/call5.8 